\title{
O EMPREGO DA FOTOGRAFIA COMO MÉTODO DE ANÁLISE DA TRANSFORMAÇÃO DA PAISAGEM O CASO DE ANCHIETA
}

\author{
THE USE OF PHOTOGRAPHY AS AN ANALYSIS METHOD OF THE \\ LANDSCAPE TRANSFORMATION - ANCHIETA'S CASE
}

\author{
Giovani Bonadiman Goltara* \\ Eneida Maria Souza Mendonça**
}

\begin{abstract}
RESUMO
A imagem fotográfica, desde o início de sua utilização, é aceita pelo censo comum - e em parte pelo meio técnico-científico - como imagem da realidade. Contudo, o processo criativo do fotógrafo é pautado em ações que podem gerar ambiguidades. Este artigo vincula-se à pesquisa sobre a transformação da paisagem contemporânea, focada no município de Anchieta como nova fronteira metropolitana ao sul da Grande Vitória, no Estado do Espírito Santo, no Sudeste do Brasil, e tem como objetivo avaliar o potencial da utilização da fotografia nos estudos relacionados à paisagem. A metodologia aqui utilizada envolveu uma revisão bibliográfica acerca do emprego da fotografia como expressão da realidade e de sua utilização em trabalhos técnico-científicos. Através da identificação de fotografias de Anchieta comparadas com estudos históricos e de evolução da ocupação do município, concluiu-se que, embora sejam sujeitas a questões relacionadas à veracidade ou confiabilidade, as fotografias são capazes de remontar a história da transformação da paisagem de forma eficaz.
\end{abstract}

Palavras-chave: Paisagem. História. Fotografia.

\begin{abstract}
The photographic image, since de beginning of its utilization, is accepted by de common sense, and in part, also by the technical-scientific circle, as image of reality. However, photography creative process is guided by actions that might create dualities. This article is linked to the research of contemporary landscape transformation, focusing on Anchieta's municipality as the new metropolitan frontier of Great Vitória-ES, southeast Brazil and investigates the potential of the utilization of photography in the landscape-related studies. The methodology involved literature review about the employment of photography as an expression of reality and it utilization in technical-scientific works. Through identification of Anchieta's photographs in comparison with historical and evolution of the municipality study, was concluded that, although might be
\end{abstract}

* Arquiteto urbanista e mestrando em Arquitetura e Urbanismo pela Universidade Federal do Espírito Santo (UFES). Rua Desembargador Antônio Tápias, 35, apart. 703, 29090-615, Jardim Camburi, Vitória, ES, Brasil.

giovani.goltara@gmail.com

** Arquiteta urbanista pela Universidade Federal do Rio de Janeiro (UFRJ). Mestra e doutora em Arquitetura e Urbanismo pela Faculdade de Arquitetura e Urbanismo da Universidade de São Paulo (FAUUSP). Pós-doutorado pela Universidade Federal Fluminense (UFF) e pela UFRJ. Professora associada no Departamento de Arquitetura e Urbanismo da Universidade Federal do Espírito Santo (UFES). Centro de Artes, CEMUNI 3, NAU. Avenida Fernando Ferrari, s/n, 29060-900, Campus Goiabeiras, Vitória, ES, Brasil. eneidamendonca@gmail.com 
bound to veracity or reliability issues, the photographs are capable to remount the landscape transformation history in an effective manner.

Keywords: Landscape. History. Photography.

\section{INTRODUÇÃO}

Este artigo tem como finalidade trazer para a pesquisa sobre transformação da paisagem contemporânea, com foco em Anchieta, a discussão sobre o método de análise da paisagem urbana por meio da fotografia. A imagem fotográfica, desde o início de sua utilização, é aceita pelo senso comum - e em parte pelo meio técnico-científico como imagem da realidade. Contudo, seu processo criativo é pautado em ações que podem gerar algumas ambiguidades. Desde a intenção de sua execução até o momento da realização, existem várias escolhas que ditam o resultado final da imagem.

Muitos fotógrafos, conscientes do efeito da fotografia sobre a percepção humana, utilizam sua arte/técnica com a finalidade de se expressar artisticamente, de criar ou modificar realidades. Um exemplo de artifícios para alcançar esses fins foi a utilização, na passagem do século XIX para o XX, da fotografia como campanha para a modernização das cidades brasileiras, transformada em cartão-postal, publicada em jornais, sempre referenciando ideais de cidade e costumes que advinham da Europa. Kossoy (2002) chama atenção para a utilização de imagens como essas no processo de reconstituição histórica, que, ao ser feito com documentos fotográficos sem o conhecimento crítico do método, das motivações e intenções do fotógrafo, pode gerar informações e conclusões equivocadas.

Por outro lado, é preciso admitir que a fotografia se mostra útil para registrar momentos específicos da vida pessoal, servindo de importante vínculo com a memória de acontecimentos privados ou públicos e para documentar procedimentos relativos a determinados tipos de estudos técnicos. Nesse contexto, é possível verificar tanto a recuperação de fatos históricos a partir de pesquisas em acervos fotográficos pessoais, como a realização intencional da fotografia através de pesquisas em diversos campos do conhecimento. No campo biomédico, por exemplo, é possível monitorar o desenvolvimento de determinada experiência ou registrar situações antes e depois de ocorrida alguma intervenção. No campo dos estudos urbanísticos, o registro fotográfico vem sendo importante para o conhecimento da história e da evolução urbana e para o estudo das técnicas construtivas características de cada tempo ou como fonte de pesquisa para estudos socioambientais. A fotografia também pode trazer elementos fundamentais para estudos relacionados à história política e social, a modos de vida da população e seus costumes.

Diante de enorme elenco de possibilidades de aplicação da fotografia em termos técnicos, a despeito das limitações reconhecidas, inicialmente mencionadas, este estudo se debruça sobre a utilização da fotografia para investigações relacionadas à paisagem. Nesse caso busca-se, na imagem fotográfica, não só a ilustração, mas o potencial de documentar o instante - talvez único -, a captação do olhar que contempla uma paisa- 
gem, a experiência do percurso e das descobertas de novas paisagens, a demonstração da proposta de um futuro diferente para determinada vista.

Propõe-se, aqui, a indagação do método do estudo historiográfico como forma de compreensão, por meio da fotografia, da paisagem em Anchieta, município localizado no litoral sul do Estado do Espírito Santo, Sudeste do Brasil - que, ao longo de sua história, passou por momentos de grande importância no cenário estadual, chegando à atualidade como expoente da produção industrial de mineração no país.

Essa abordagem foi desenvolvida ao longo deste artigo abrangendo, inicialmente, o debate acerca do questionamento relacionado à fotografia como expressão da realidade. Em seguida, a despeito das limitações percebidas, buscou-se demonstrar a aplicação do registro fotográfico como fonte de estudos técnicos e pesquisas relativas à cidade. Percorre-se, aqui, a título de experimentação, aspectos da evolução urbana de Anchieta associados a imagens fotográficas.

\section{FOTOGRAFIA: EXPRESSÃO DA REALIDADE?}

A fotografia, desde o século XIX - quando Daguerre criou a câmara escura e Niépce logrou a fixação de uma imagem em placa de estanho -, tornou-se símbolo da expressão da realidade, causando enorme impacto nos meios artísticos e intelectuais. Em 1859, Charles Baudelaire criticou a adesão do povo francês à fotografia como símbolo da modernidade e a crença de que era a única forma de reproduzir a realidade da natureza:

Em matéria de pintura e de escultura, o Credo atual do povo, sobretudo na França (e não creio que alguém ouse afirmar o contrário) é este: "Creio na natureza e creio somente na natureza (há boas razões para isso). Creio que a arte é e não pode ser outra coisa além da reprodução exata da natureza (um grupo tímido e dissidente reivindica que objetos de caráter repugnante sejam descartados, como um penico ou um esqueleto). Assim, o mecanismo que nos oferecer um resultado idêntico à natureza será a arte absoluta". Um Deus vingador acolheu as súplicas desta multidão. Daguerre foi seu Messias. E então ela diz a si mesma: 'Visto que a fotografia nos dá todas as garantias desejáveis de exatidão (eles creem nisso, os insensatos), a arte é a fotografia'. (BAUDELAIRE, 1859. Disponível em: <http://www.entler.com. br/textos/baudelaire2.html>. Acesso em: 23 nov. 2015).

Graças à sua natureza físico-química, e hoje eletrônica, de registrar aspectos do real, a fotografia ganhou elevado status de credibilidade. Se, por um lado, tem valor incontestável da representação do homem ou da atuação do homem sobre outros homens e sobre a natureza, por outro, sempre se prestou e sempre se prestará aos mais diferentes e interesseiros usos dirigidos (KOSSOY, 2002). A imagem fotográfica depende de componentes que possibilitem sua existência no mundo: o assunto, que é o objeto do registro; a tecnologia, que viabiliza tecnicamente o registro; o fotógrafo, o autor, quem a idealiza por meio de processos cultural/estético/técnico. (KOSSOY, 2002). 
Cada componente do processo fotográfico, embora não independentes, possibilitam resultados distintos, sendo o produto final a combinação das escolhas tomadas em cada componente. Contudo, a fotografia representa um referente, que, para Barthes (1984), não é a coisa facultativamente real para a qual se remete uma imagem ou signo, mas a coisa necessariamente real - colocada diante da objetiva -, sem a qual não haveria fotografia.

Segundo Sontag (1986), as fotografias fornecem provas, passam a ser provas incontroversas de que determinada coisa aconteceu. Porém, há, no registro do referente, uma série de parâmetros que geram diversas interpretações da imagem fotográfica. As fotografias não são meros espelhos mudos e inocentes daquilo que flagram. Embora tenham, de fato, certo poder de duplicar o real, essa duplicação gera ambiguidades indissolúveis. (SANTAELLA, 2005). As fotografias são criadas a partir de escolhas. Em geral, existe um interesse específico, uma intenção no registro de algum assunto determinado. Elas são plenas de ambiguidades, portadoras de significados não explícitos e de omissões pensadas, calculadas. Portanto, não devem ser aceitas imediatamente como espelho fiel dos fatos. (KOSSOY, 2002).

Kossoy (2002) defende que as diferentes ideologias sempre tiveram, na fotografia, um poderoso método para divulgação de ideias e a consequente formação e manipulação da opinião pública. $O$ cartão-postal, amplamente disseminado no início do século XX - chegando a milhões na França -, exemplifica o uso da fotografia na divulgação de imagens de cidades. Além da disseminação das imagens, era passível de coleção, o que ampliou o seu consumo. São Paulo é um exemplo de cidade que utilizou em larga escala os cartões-postais para se impor no cenário como uma cidade moderna. Importados da Europa, a arquitetura, a moda, os costumes retratavam-se nos cartões para o restante do Brasil e para o exterior.

De acordo com Prado (2004), o traço marcante da modernização brasileira foi seu caráter imagético, pelo qual o ideal de modernidade, muitas vezes, resumia-se a um cenário que criasse tal atmosfera. Em artigo intitulado "A modernidade e seu retrato", o autor busca assimilar como a fotografia prestou o serviço de criar a atmosfera imaginária da cidade de Vitória, capital do Espírito Santo, em seu momento de modernização, entre 1890 e 1950. As fotografias contribuíram para a concretização da ação física sobre o espaço urbano, não somente por documentarem as modificações na cidade de Vitória, mas também por atuarem na difusão do ideal de modernidade, introduzindo no cotidiano capixaba imagens de outros centros, com desenhos urbanos já modernizados, sua arquitetura, costumes, contribuindo para formar nas mentes a imagem do que seria a cidade ideal moderna.

Testemunhar as transformações na paisagem urbana de Vitória foi tarefa muito bem conduzida pelos fotógrafos - amadores ou profissionais - contratados para produzir postais, álbuns ou registrar obras públicas. Homens que, através do seu trabalho, perpetuaram a beleza da cidade ou até mesmo indicaram os caminhos para seu progresso - mesmo que esse último não tenha sido seu objetivo consciente. (PRADO, 2004, p. 91). 
Os postais e fotos autorais examinados por Prado (2004) em seu estudo focavam seletivamente os palacetes públicos, posicionados sobre seus eixos centrais, ocultando o que ainda não havia sido renovado, numa composição equilibrada. Dessa forma, tentou-se criar uma imagem da cidade de Vitória que não correspondia totalmente à realidade e destacar intervenções pontuais no tecido urbano e obras arquitetônicas e costumes relativos a uma classe social minoritária.

Nesse sentido, Kossoy (2002) alerta que a reconstituição histórica a partir do documento fotográfico não pode ser entendida ao primeiro olhar; deve ser feita uma análise cuidadosa, levando em consideração o processo criativo do fotógrafo, desde a intenção da fotografia, seja por encomenda ou desejo pessoal, até as escolhas de quadro, equipamentos e técnica.

A despeito dessas considerações, que questionam a relação entre fotografia e realidade, é frequente e fundamental a aplicação do documento fotográfico em pesquisas científicas e trabalhos técnicos de diversas áreas do conhecimento. Procurando explorar esse potencial, buscou-se tratar - antes de abordar de modo específico a aplicação da mesma no estudo sobre a cidade de Anchieta - da utilização da fotografia como fonte metodológica em pesquisas científicas e como registro em trabalhos técnicos relacionados à área de arquitetura e urbanismo.

\section{FOTOGRAFIA - FONTE EM PESQUISA CIENTÍFICA E REGISTRO EM TRABALHO TÉCNICO RELACIONADO À CIDADE}

Ao mesmo tempo em que a fotografia se desenvolve, afirma-se como meio artístico expressivo, em que a realidade fotografada é exibida a partir de ângulos, pontos de vista e efeitos que transformam o elemento registrado em arte. Concomitantemente, a utilização da fotografia evolui como registro de situação específica para documentar a verdade de determinado momento. Mesmo reconhecendo que a verdade, assim documentada, seja relativa, a fotografia vem se constituindo em meio que propicia avanços em estudos e projetos relacionados à vida urbana.

Nota-se atualmente que, após anos de evolução do material técnico para a execução da fotografia, esta se tornou uma forma rápida e acessível de captação da imagem e seu uso foi amplamente difundido. No entanto, a utilização da imagem fotográfica em pesquisas científicas e trabalhos técnicos não se detém a compor trabalhos como ilustração de ideias. Em muitos casos, a fotografia faz parte do método de apreensão de determinado assunto e demonstração propositiva do mesmo. Tal é o caso de estudos relacionados à paisagem. Pode-se dizer, em termos gerais, que a paisagem é a imagem resultante da síntese dos elementos presentes em um espaço territorial abrangido pelo olhar e que a câmera fotográfica, em seu registro, emula o olhar. Ao fotografar, enquadra-se determinada fatia do conjunto de elementos escolhidos pelo autor do registro. Assim sendo, a câmera fotográfica mostra-se importante instrumento para a apreensão da paisagem e de seus elementos constitutivos. 
Gordon Cullen (1983) trata a visão como principal forma de apreensão da paisagem urbana. Entre os aspectos da experiência visual da paisagem destacados pelo autor encontra-se a ótica, que, no percurso do transeunte pela cidade, se desenvolve em sucessão de pontos de vista: "A paisagem urbana surge na maioria das vezes como uma sucessão de surpresas ou revelações súbitas. É o que se entende por VISÃO SERIAL" (CULLEN, 1983, p. 11). Para exemplificar e estudar de forma aprofundada cada um desses pontos de vista, o autor se utiliza de fotografias em série (figura 1), exprimindo a experiência da caminhada por determinado percurso:

Ipswich [cidade britânica]: um modesto arco funciona como elemento de separação no terreno que estamos a explorar. De um lado a parte da rua em que nos encontramos; para lá do arco, o espaço aonde iremos desembocar, transitando então para uma nova ambiência. (CULLEN, 1983, p. 21).
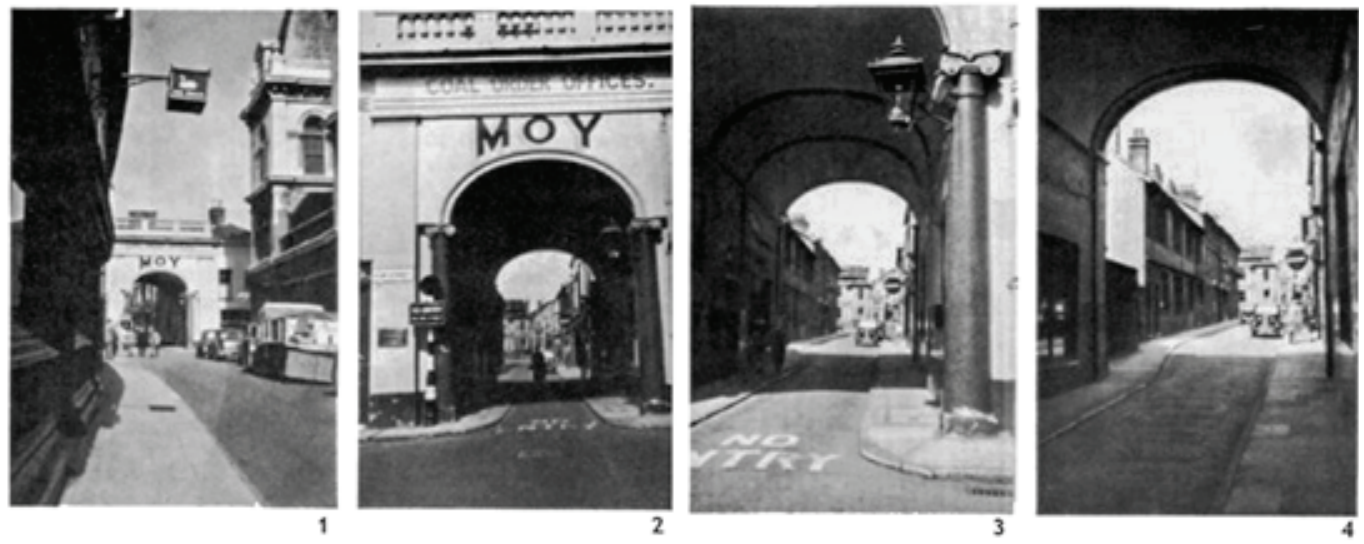

Figura 1 Fotografias sequenciais em Ipswich. Fonte: Cullen (1983, p. 22).

Del Rio (1990) realiza abordagem semelhante ao aplicar a visão serial proposta por Cullen (1983) no estudo que envolve percurso urbano no centro da cidade do Rio de Janeiro, na praça Quinze, ao longo do beco emoldurado pelo Arco do Teles (figura 2).

As fotografias sequenciais podem, também, ser utilizadas para pesquisas com outros fins. Nesse sentido, é ainda Del Rio (1990) que, entre outros autores, chama atenção para a possibilidade de realização de fotografias sequenciais - para estudo classificado na categoria comportamento ambiental - a fim de compreender as relações do usuário com elementos arquitetônicos e o espaço urbano. Nessa análise, os métodos de registro do comportamento são subdivididos em diretos ou indiretos. Podem ser classificados como diretos aqueles que registram o momento da ocorrência através de fotografia, desenho, vídeo. São considerados indiretos aqueles que o fazem depois da utilização do ambiente, identificando pistas das ocorrências. No caso do registro direto, no entanto, a sequência de fotografias é efetuada do mesmo ponto de vista, com o intuito de documentar o comportamento do usuário de determinado ambiente para exame posterior. Esse tipo de estudo é útil, por exemplo, nos casos de reestruturação arquite- 
tônica, urbanística ou paisagística de espaços públicos, ou mesmo privados. Trata-se de observação e documentação fotográfica, realizadas durante várias horas, ou vários dias, acerca do funcionamento e da utilização do espaço em questão, também denominado "palco da cena". Esse tipo de experiência também é inerente à psicologia ambiental, pela oportunidade de analisar características do ambiente retratado e possíveis efeitos sobre o comportamento humano.


Figura 2 Arco do Teles e Beco do Comércio, Praça XV, Rio de Janeiro, RJ, Brasil.

Percepção do percurso como série de quadros visuais sucessivos: a intensidade de alterações nos quadros corresponde a maiores apelos e interesse para o pedestre.

Fonte: Del Rio (1990, p. 87).

Desse modo, a documentação fotográfica do comportamento ambiental permite estudos sobre apropriações de praças, parques, estações de trem ou de ônibus, escolas, asilos, prisões, auxiliando a identificar inadequações e potencialidades que possam servir de base para a proposição de um ambiente mais adequado ao uso à que se destina.

Para a observação direta são necessários procedimentos sistematizados. Entre eles, encontra-se a posição do observador em relação ao observado, que pode ser: de fora do acontecimento e oculto; de fora, mas reconhecido; participante marginal ou eventual; participante total no acontecimento. Outro procedimento importante refere-se aos instrumentos do registro, que, além da fotografia, podem envolver notações, mapas, filmes e vídeos. É importante possuir definição prévia sobre: 0 quê observar, a quem observar, fazendo o quê, com quem, quais as relações entre 
eles. (DEL RIO, 1990). Interessa, também, dar destaque à abordagem investigativa proposta por Ferrara (1999) em atividade de caráter participativo. Ao envolver a população de determinada comunidade em estudo sobre a paisagem do lugar, a autora distribuiu, entre os membros da população, máquinas fotográficas para que registrassem os elementos que consideravam mais significativos. Davi Protti, fotógrafo e professor do curso de Comunicação Social da Universidade Federal do Espírito Santo (UFES), realizou experiência semelhante à de Ferrara. Em atividade com a comunidade de baixa renda, em convênio com a Prefeitura Municipal de Vitória, o professor ministrou oficinas para jovens participantes de programas sociais. Nelas, foram ensinadas noções básicas de fotografia, resultando em atividade prática com uso de câmeras fotográficas pelos jovens para registro da paisagem da cidade relacionada a seu bairro. As fotografias, ainda como parte do curso, foram selecionadas pelos participantes, culminando em uma exposição das mesmas no interior de alguns ônibus municipais. Segundo o professor, o objetivo não se resumia ao manuseio da máquina e ao desenvolvimento da técnica fotográfica, pois também estimulava o desenvolvimento da observação e o debate sobre a paisagem da cidade.

No campo da pesquisa relacionada à análise e construção da paisagem, Mendonça (2005) utiliza a fotografia em diversas circunstâncias. $\bigcirc$ estudo desenvolvido pela autora visa, basicamente, à estruturação de métodos para identificação de referenciais da paisagem e proposição de formas de ocupação que permitam o desenvolvimento urbano garantindo a manutenção da visibilidade e da acessibilidade aos referenciais identificados. $\bigcirc$ método em estudo "[...] pauta-se na ideia que relaciona a conservação da paisagem à manutenção da identidade e ao fortalecimento da cidadania". (MENDONÇA, 2005, p. 7).

Uma das aplicações da fotografia nesta pesquisa refere-se ao exame de relatos de viajantes que, na segunda metade do século XIX, percorreram a costa do Espírito Santo, ou visitaram a cidade de Vitória, documentando seus escritos sobre a paisagem com fotografias. Outra aplicação da fotografia, no método de Mendonça (2005), diz respeito ao mapeamento de percursos em torno do elemento referencial da paisagem em estudo, procurando registrar as áreas comprometidas com a visibilidade do mesmo e os respectivos pontos de vista de onde essa visibilidade pode ser vislumbrada. São realizadas fotografias de cada ponto de vista registrado para posterior exame e classificação da paisagem a partir de níveis de percepção estabelecidos pelo método.

Desse modo, após escolhidos os referenciais paisagísticos a serem preservados, foram eleitos pontos de vista privilegiados, de onde se almejava manter a visibilidade, para então propor a ocupação urbana com limites de altura e implantação que a garantissem. Para definir a visibilidade almejada, mostraram-se úteis os estudos realizados sobre as fotografias efetuadas durante o percurso, a fim de examinar o potencial de visibilidade do afloramento rochoso em questão. As fotografias foram examinadas, separadas em grupos e classificadas em níveis de percepção (figura 3) de acordo com a forma e dimensão visível do elemento em estudo. Para Mendonça (2005, p. 9): 

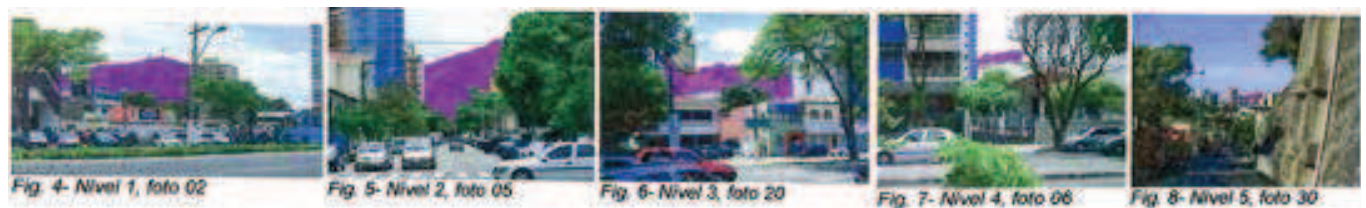

Figura 3 Níveis de percepção do morro do Guajuru, Vitória, ES. Fonte: Eneida Mendonça (2005, p. 14).

A partir dos registros fotográficos é possível desenvolver classificação abordando níveis de percepção do elemento paisagístico em foco, adotando-se, por exemplo, gradação entre níveis mais amplos e mais restritos. Essa classificação permite conhecer a intensidade bem como a vulnerabilidade da percepção do elemento em análise, resultando em instrumental para avaliação, debate e decisão.

Na aplicação desse método em trabalho técnico realizado por demanda da Prefeitura de Vitória (ES), o uso da fotografia foi aprimorado. O plano, intitulado "Plano de proteção da paisagem da área central de Vitória", utilizou fotografias para a escolha dos pontos de vista que privilegiassem os elementos arquitetônicos com potencial patrimonial e tecnologias de manipulação e criação de imagens, tendo como referência a fotografia, para simular o resultado da proposta de normas e diretrizes urbanísticas (figura 4).

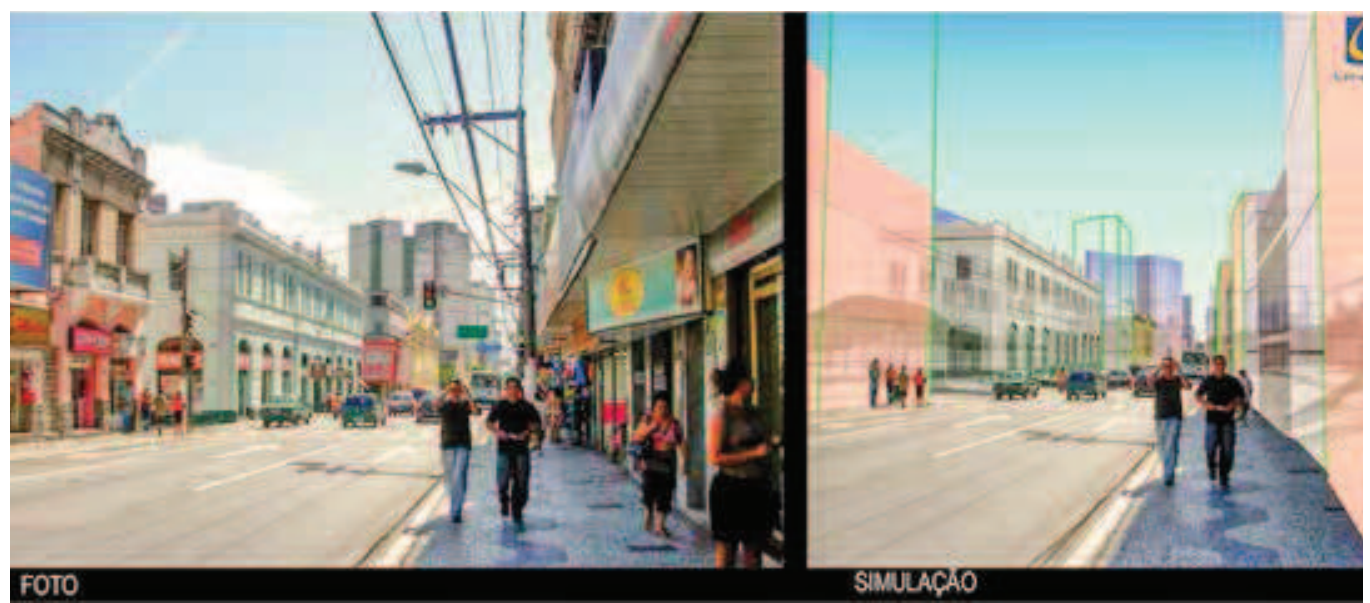

Figura 4 Simulação gráfica da proposta de preservação visual do Mercado da Capixaba.

Fonte: Plano de proteção da paisagem da área central de vitória. SEDEC/PMV e NAU/UFES - 2010.

A figura 4 é um dos exemplos de utilização da fotografia para proposição de diretrizes. Nesse caso, as cores representam as propostas: a azul representa edifícios de grande porte não considerados prováveis de demolição para substituição por outra construção; os acréscimos em tons de rosa representam a possibilidade de inserção de novas edificações, mantendo a visibilidade dos referenciais da paisagem a partir de pontos de vista selecionados com foco em eixos de intensa circulação ou permanência de pessoas; a linha de contorno verde indica o índice de altura instituído pela 
normativa do Plano Diretor Urbano de Vitória vigente à época de realização do estudo. (CAMPOS, 2010).

Existem outras técnicas que usam a fotografia como importante possibilidade de conhecimento da história e de monitoramento dos processos de ocupação urbana e transformação da paisagem. Entre elas, o exame de fotografias que retratam determinado ambiente em várias datas. $\bigcirc$ exame comparativo de vistas aéreas, aerofotogrametrias e, mais recentemente, imagens de satélite - de datas distintas - vem permitindo a evolução da técnica de análise da ocupação do território a partir do aprimoramento, da difusão e da popularização da utilização da fotografia. Algumas técnicas, abordadas a seguir, embasaram o estudo realizado sobre a transformação da paisagem urbana de Anchieta, município de pequeno porte situado no sul da Região Metropolitana de Vitória (RMGV), que vem recebendo impactos ligados ao processo de industrialização ocorrido no Estado do Espírito Santo.

\section{BREVE EVOLUÇÃO URBANA DE ANCHIETA A PARTIR DA FOTOGRAFIA}

Anchieta é uma cidade litorânea situada no sul do Estado do Espírito Santo, Sudeste do Brasil. Sua fundação remonta ao século XVI, com a chegada dos colonizadores portugueses que instituíram um homônimo aldeamento às margens do rio Benevente. A decisão de catequizar os nativos - que formavam uma das maiores tribos indígenas do Estado na época - levou a Anchieta os missionários jesuítas. Ali fundaram um polo de sua ordem, que integrava o ramal sul do próspero complexo com sede em Vitória.

Entre os poucos relatos imagéticos desse período, existe uma pintura do século XVII (figura 5) na qual se vê a igreja e o colégio dos jesuítas - hoje igreja e museu - no local onde estão presentes até hoje. Na imagem, não há referências aos índios - que aparecem no relato de D. Pedro Maria de Lacerda sobre sua visita a Anchieta, mais tarde, em 1886: "Devo dizer que outrora nos princípios a população Indiana estava toda sobre o Monte, e por ali se estendiam as choupanas dos Índios [...]". (NEVES, 1997, p. 26). Além da ausência dos índios e suas choupanas, nota-se que também o morro foi retirado da cena, que mostra a edificação entre o rio e o mar, bem mais próximo destes do que na realidade. Verifica-se, então, que a manipulação da imagem real na pintura é um processo que se sobressai à fotografia, já que na própria criação o pintor se utiliza de suas técnicas para produzir a imagem como a interpreta ou deseja perpetuar.

Os primeiros relatos fotográficos do final do século XIX sugerem que a ocupação no centro de Anchieta se manteve pouco modificada em relação ao descrito no passado. Em meados desse século, o rio Benevente tornou-se importante canal de escoamento da produção agrícola do interior do município. Nas primeiras fotografias localizadas (figura 6), já se percebe um núcleo urbano modesto, porém bem adensado, nos arredores das instalações portuárias, o que confirma o desenvolvimento de atividades relacionadas à demanda portuária, como galpões de estocagem e casas de comércio. 


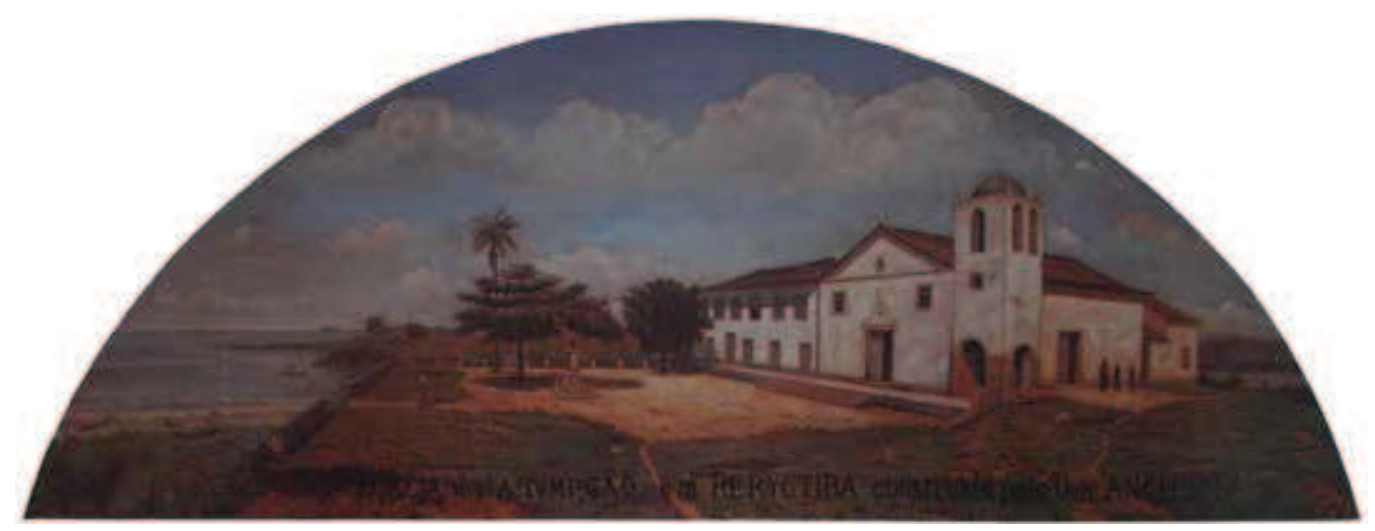

Figura 5 Pintura do século XVII do complexo jesuítico de Anchieta. Fonte: Autor desconhecido. Mattos (2006, p. 35).

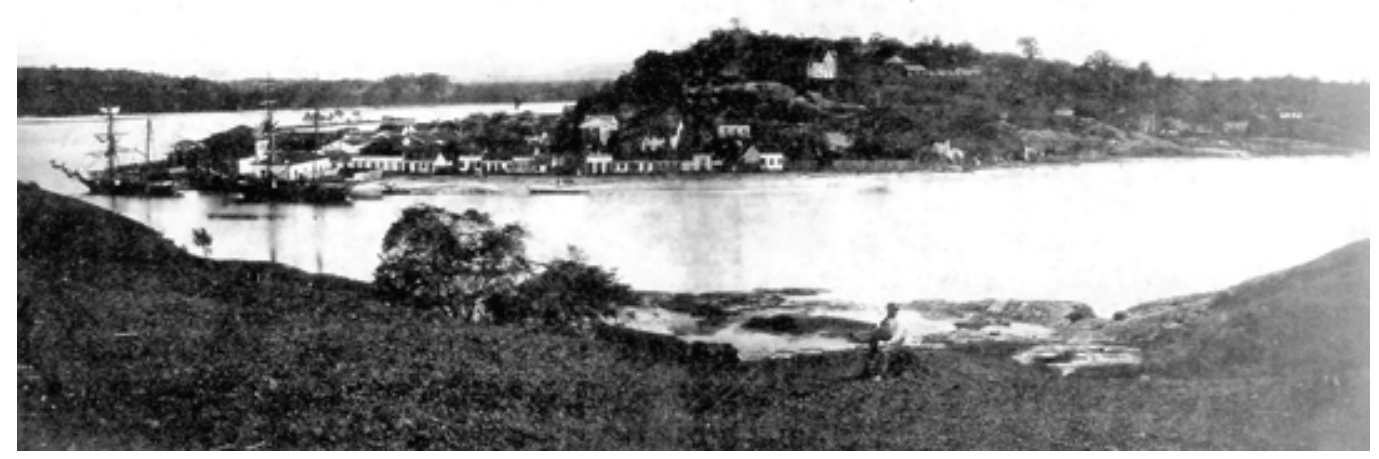

Figura 6 Foto de Anchieta no final do século XIX.

Fonte: Autor desconhecido - Acervo do Museu Municipal de Anchieta

O ponto de vista escolhido para a maioria das imagens localiza-se na parte sul do município, na margem do rio Benevente oposta ao centro (figura 7). Esse ponto de vista da cidade é recorrente em diversos períodos da história, desde as primeiras fotografias do final do século XIX até o final do século XX, ocasião em que a igreja e suas imediações ganharam maior importância no cenário turístico da cidade. Pode-se concluir que esse local seria um importante ponto de observação da paisagem urbana de Anchieta nas suas diversas transformações.

Do final do século XIX até meados do século XX, os esforços empreendidos pelo Governo do Estado do Espírito Santo tinham o objetivo de direcionar para Vitória o escoamento da produção agrícola exportável, tornando a capital, de fato, o centro econômico e político-administrativo do Estado. (CAMPOS JUNIOR, 1996; MENDONÇA et al., 2009). Com isso, o porto de Anchieta, gradativamente, perdeu sua importância. Nas fotografias desse período, percebe-se que o foco já não é o porto e nem o centro da cidade. Mantendo-se igual ponto de vista, o olhar desloca-se para a direita, tendo o complexo jesuítico como referencial - acrescentando-se o colégio Maria Mattos, fundado em 1932 (MATTOS, 2006), e o Hotel Anchieta, fundado em 1940 (figura 8). 
Conforme Mendonça e Goltara (2012, p. 4):

O Colégio contribuiu para incrementar o caráter institucional da parte alta da cidade, enquanto o hotel, além de complementar ao uso escolar, lançou a possibilidade do estabelecimento de novo uso, o de balneário, que caracterizou a região em período seguinte.

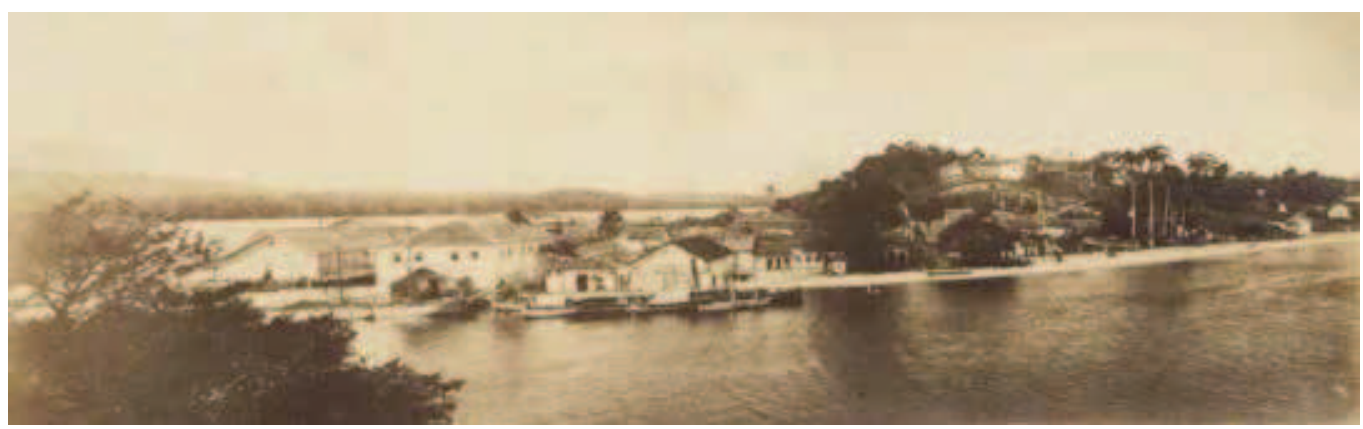

Figura 7 Foto de Anchieta - 1910

Fonte: Autor desconhecido - Acervo do Museu Municipal de Anchieta

A figura 8, além de retratar o novo centro institucional do município, traz um relato importante para compreender a dinâmica da mobilidade entre uma margem e outra do estuário do rio Benevente: a travessia. $\bigcirc$ momento dessa fotografia, espontâneo ou não, sugere a intenção do fotógrafo de relacionar o colégio e a forma em que os estudantes ali chegavam antes de haver conexão física entre as duas margens.

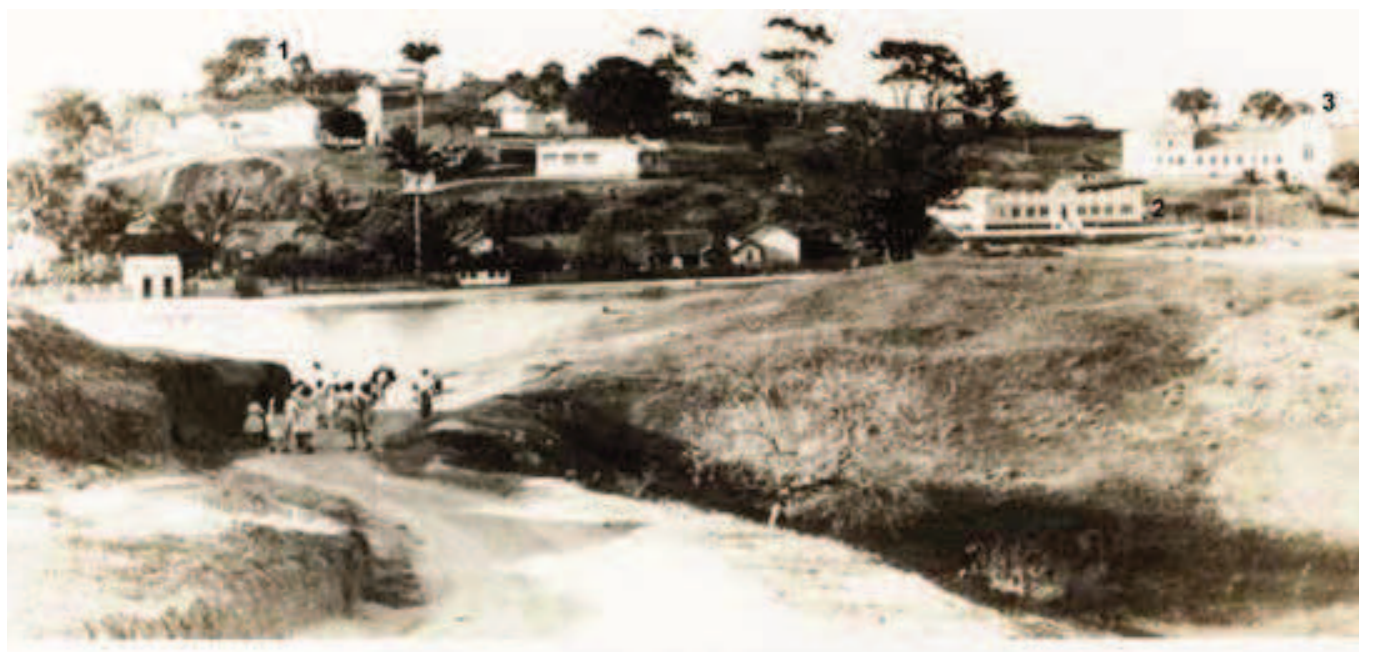

Figura 8 Foto de Anchieta nos anos 1950 (1-igreja; 2-colégio; 3-hotel).

Fonte: Autor desconhecido - Acervo do Museu Municipal de Anchieta

Em 1954, inaugura-se em Anchieta a ponte Cônego Barros (NEVES et al., 1995), marca do processo de implementação da política voltada para o transporte rodoviário, instituída no Brasil ao longo do século XX. (MENDONÇA; GOLTARA, 2012). A partir de 
então, e durante algum tempo, esse novo elemento, marcante na paisagem, tornou-se presença obrigatória na maioria das fotografias (figura 9), provavelmente como forma de enaltecer o progresso e celebrar a facilitação da travessia de um lado ao outro do município. Nos anos que se seguiram, a agricultura se manteve como principal atividade econômica do município e o turismo começou a se desenvolver, principalmente focado nas praias de Iriri (figura 10), Ubu e Castelhanos, fora do centro urbano. Nesse momento, a fotografia, além de ter se tornado mais acessível, começou a ser utilizada para retratar excursões turísticas - atualmente mostrando-se como um dos principais focos da produção de imagens.

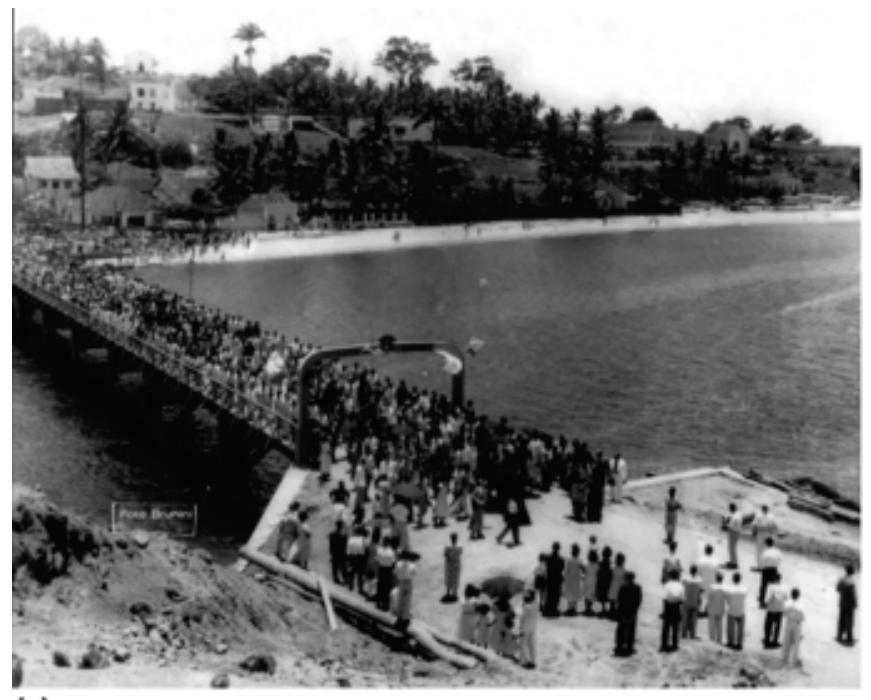

(a)
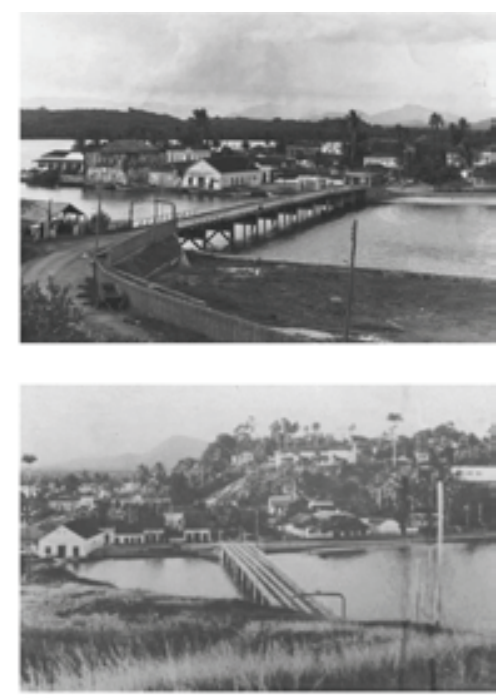

(b)

Figura 9a Foto da cerimônia de inauguração da ponte "Cônego Barros" - 1954

Fonte: Foto Brunini - Acervo do Museu Municipal de Anchieta

Figura 9b Fotos de Anchieta nos anos 1950.

Fonte: Autor desconhecido - Acervo do Museu Municipal de Anchieta

A saída da crise do modelo agrário almejado pela elite política estadual e local em Anchieta favoreceu a instalação da indústria de pellets da Samarco Mineração, em 1977 (BARBOSA, 2010), e do complexo portuário de Ubu. No decorrer desta pesquisa, foi encontrada a primeira fotografia aérea do município, de 1970 (figura 11), realizada para o mapeamento agrário do Estado do Espírito Santo. Nessa foto, percebe-se que a administração da cidade parece especular sobre a possibilidade de intenso desenvolvimento, criando novos loteamentos para bairros residenciais, com função de balneários, executando novos projetos de urbanização (figura 12).

As instalações industriais e portuárias da empresa mineradora SAMARCO (figura 13), por se localizarem fora do que nos anos de 1970/1980 era o núcleo urbano da cidade, não se conectam imageticamente nas fotografias da cidade. Por outro lado, no final do século XX, o principal elemento presente nas fotografias voltou a ser o complexo jesuítico (figura 14), tombado em 1941 como patrimônio da Memória Nacional pelo 
Instituto do Patrimônio Histórico e Artístico Nacional, e restaurado em 1994 (http://www. litoralsulcapixaba.com.br/), se tornando de fato o "cartão-postal" da cidade.
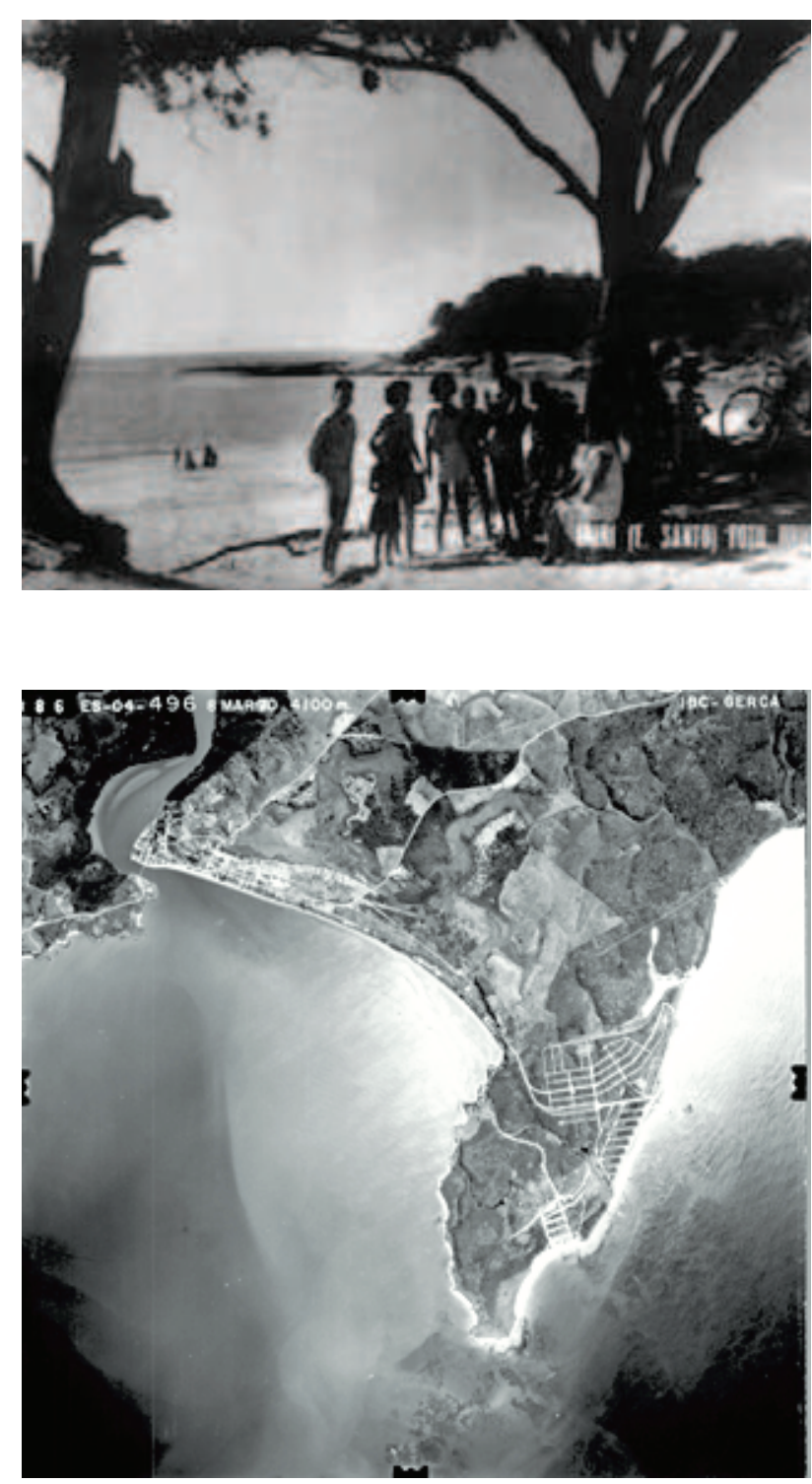

Figura 10 Banhistas em uma das praias de Iriri, nos anos 1960.

Fonte: Foto Brunini - Acervo do Museu Municipal de Anchieta
Figura 11 Fotografia aérea do município de Anchieta em 1970.

Fonte: Instituto de Defesa Agropecuária e Florestal do Espírito Santo (IDAF).

No que se refere ao desenvolvimento da ocupação urbana de Anchieta, observou-se, a partir dos anos 1970, o adensamento das áreas já existentes (figura 15). Ao longo dos anos, o parque industrial da Samarco foi ampliado, e, para o futuro, existem previsões de outras ampliações, além da instalação de uma nova indústria de mineração da Vale (antiga Companhia Vale do Rio Doce) - ainda em fase de aprovação, apresenta conflitos com o ecossistema do local. (MENDONÇA; GOLTARA, 2012). A figura 15 reproduz aspectos recentes da paisagem da sede de Anchieta, deixando a expectativa sobre possíveis futuras alterações. 


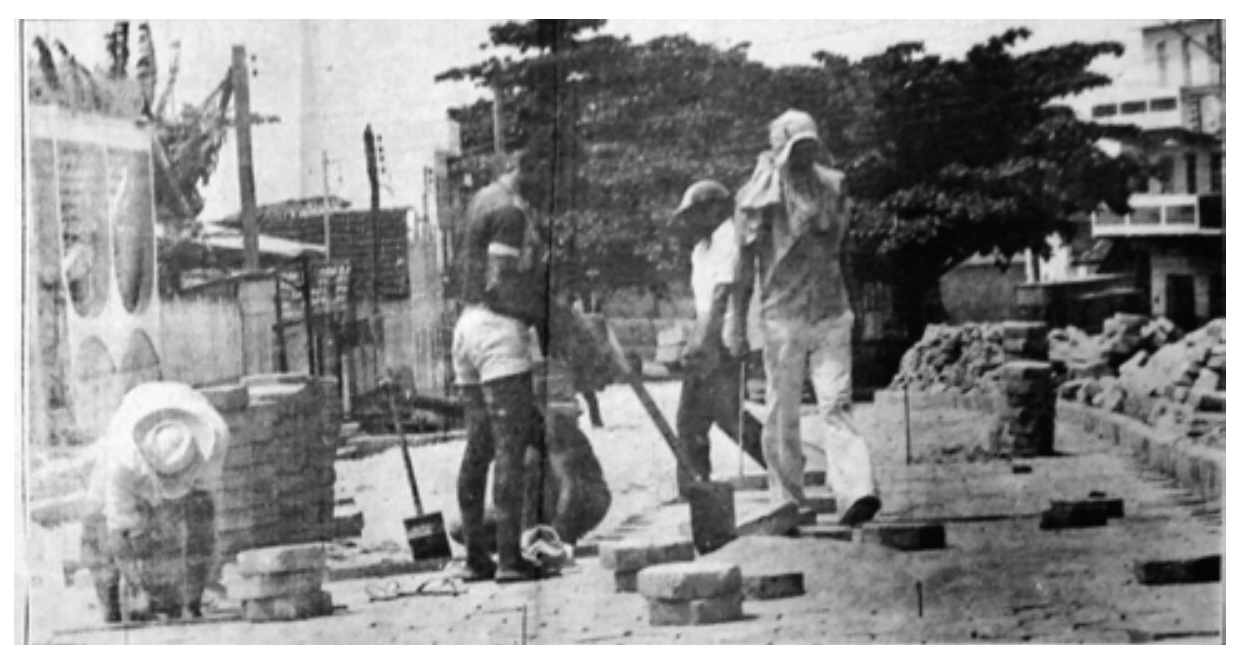

Figura 12 Operários trabalhando na pavimentação da avenida Jerônimo Monteiro em 1977. Fonte: Jornal A Gazeta (1977, p. 1).
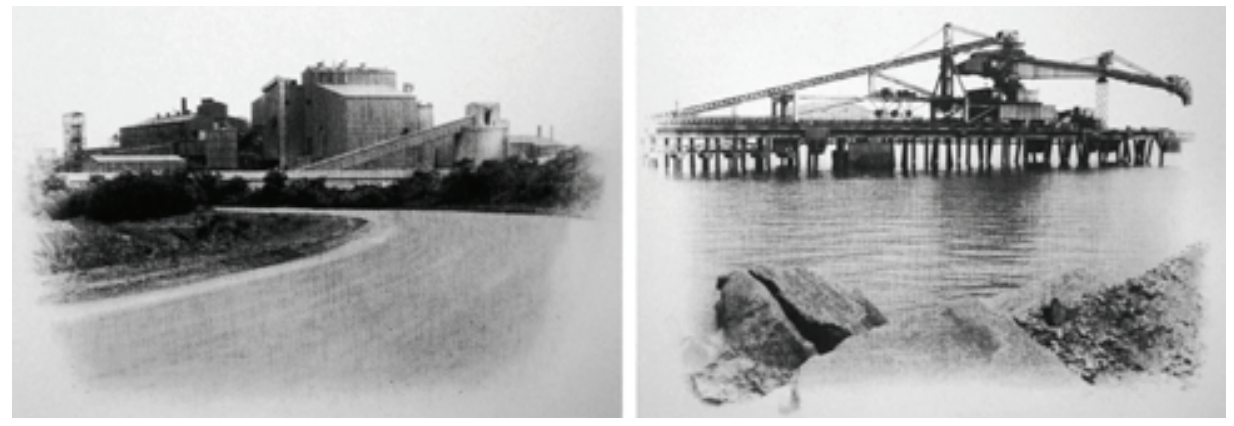

Figura 13 Fotos da indústria de pellets da Samarco e do complexo portuário de Ubu. Fonte: Carvalho (1989, p. 27).

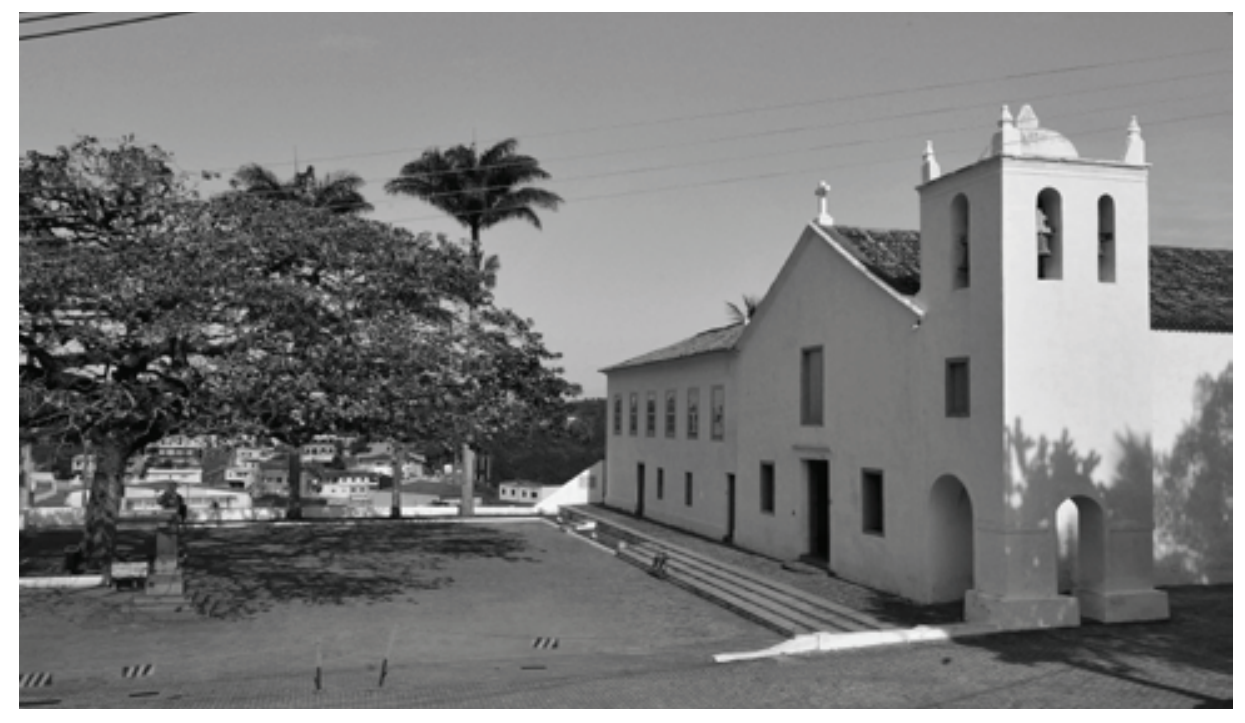

Figura 14 Foto recente da igreja e museu de Anchieta - 2011 Fonte: Elis Modolo. Acervo da pesquisa - NAU-UFES, 2011. 


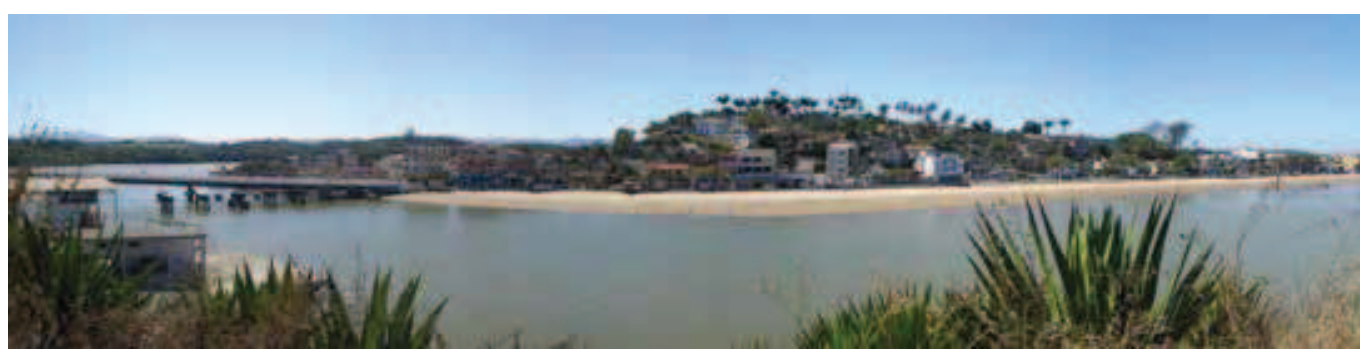

Figura 15 Panorama atual de Anchieta - 2010

Fonte: Elis Modolo. Acervo da pesquisa - NAU-UFES, 2011.

\section{CONCLUSÃO}

Este artigo contribuiu para promover alguns questionamentos sobre a fotografia como método de análise e estudo da paisagem. Para tanto foi necessário considerar as potencialidades da fotografia e suas limitações. Como exposto por Kossoy (2002), Sontag (1986) e Barthes (1984), a fotografia possui um índice real, uma prova dos fatos. A fotografia "crua" (imagem captada pela objetiva, sem manipulação) carrega o índice iconográfico, a incontestável presença do objeto fotografado e sua aparência. A massa receptora dessas imagens, ao longo dos anos, passou a aceitar a veracidade, ainda que aparente, da fotografia. Ao entender essa dinâmica de aceitação, diferentes ideologias souberam utilizar-se das imagens para propagar suas ideias, e os fotógrafos desenvolveram técnicas de manipulação pré e pós-produção para transformar o contexto do elemento fotografado, e até sua aparência. Prado (2004), ao exemplificar tais possibilidades com as imagens da modernização da cidade de Vitória, plenas de intenções e idealidades, lança uma interlocução com Kossoy (2002) no que diz respeito ao estudo historiográfico. Segundo este, para reconstituir a história de determinado local ou paisagem, deve-se levar em consideração todo o processo de criação das imagens fotográficas e seu contexto temporal com o intuito de decifrar as intenções e possíveis manipulações, assimilando, assim, suas múltiplas realidades.

Embora a fotografia seja suscetível a questões relacionadas à veracidade ou confiabilidade, muitos estudos logram sua utilização de forma eficaz. A representação do olhar em percursos, por exemplo, nas imagens sequenciais de Gordon Cullen (1983), de certa forma independe da total veracidade; o que importa, ali, é a expressão da experiência, o signo, a aparência dos lugares. Da mesma forma, ao utilizar imagens sequenciais, Del Rio (1990) trata do comportamento com interesse de documentar e estudar as ações dos indivíduos em determinados locais e suas interações. A intenção de emular o olhar é recorrente nos estudos que utilizam a fotografia. Cullen (1983) tem a intenção de levar ao leitor sua experiência de campo; os trabalhos de Ferrara (1999) e Davi Protti intencionam captar as experiências das pessoas em relação ao lugar, e, assim, guiar seus estudos. Nesse sentido, a total veracidade não influi no resultado, considerando-se, de certa forma, a intenção do fotógrafo em registrar o que vê e avalia como importante. 
O trabalho de reconstituição histórica de Anchieta a partir de fotografias, guiado por alguns conceitos relacionados à análise de imagens, ainda que em experimentações iniciais, trouxe dados importantes a serem considerados no estudo da paisagem local. $\bigcirc$ elemento principal constatado foi a localização do fotógrafo em relação à paisagem, na maioria das imagens, num plano frontal, como se fossem vislumbradas pelo "viajante" ao chegar em Anchieta. Considerando que a localização geográfica de posicionamento desses fotógrafos, nas várias fotografias examinadas, situava-se em determinada parte do município, por onde se chegava a partir do sul do Estado do Espírito Santo, é possível inferir que essa vista não só é recorrente em fotografias, como poderia ser considerada a imagem da cidade, o ícone. De modo relacional, é possível afirmar que esse local de observação pode ser percebido como um ponto de vista especial da paisagem. Esse mesmo local, como observado na figura 7, situado onde se dava a travessia de um lado ao outro do município, possivelmente era um espaço de permanência, de espera para ascender à paisagem vislumbrada.

Outro ponto importante encontra-se na veiculação das obras urbanas - para recepção da indústria nos anos 1970 - nos meios de comunicação, exemplificado na figura 12. Nesse contexto, há certa relação com a exposição de Prado (2004) sobre a modernização de Vitória, sendo que, de alguma forma, a intenção era divulgar, em mídia de alcance estadual, a preparação da cidade para o futuro. Ainda no contexto das modificações no fim do século XX, as fotografias aéreas mostram-se imprescindíveis para analisar a evolução urbana e a transformação da paisagem, que, relacionadas aos fatos históricos, permitem compreender a dinâmica do tecido urbano.

Depreende-se, deste tudo, que as fotografias, embora fascinantes ao olhar, devem ser utilizadas e analisadas de forma cautelosa; não substituem outras formas de expressões artísticas, principalmente na apreensão da paisagem. A preocupação de Baudelaire (1859), em meados do século XIX, de que a fotografia suprimisse a pintura e outras manifestações artísticas, se trazida ao contexto da paisagem, pode ser interpretada como o risco existente de que a produção rápida de imagens com câmeras fotográficas suprima o ato de observar a paisagem, de desenhá-la, e, assim, captar suas nuances. Também na reconstituição histórica, as fotografias não podem ser consideradas absolutas; elas podem ser pontos de partida para indagações e para o despertar de interesses - a serem complementados com outras técnicas.

\section{REFERÊNCIAS BIBLIOGRÁFICAS}

BARBOSA, Isabella Batalha Muniz. O lugar no contexto das redes globais: o Polo Industrial e de Serviços de Anchieta, ES: uma paisagem em transformação. 2010. 341 f. Tese (Doutorado em Arquitetura e Urbanismo) Faculdade de Arquitetura e Urbanismo da Universidade de São Paulo, São Paulo, 2010.

BARTHES, Roland. A câmara clara: nota sobre a fotografia. 2 ed. Rio de Janeiro: Nova Fronteira, 1984.185 p.

BAUDELAIRE, Charles. O público moderno e a fotografia. Disponível em: <www.entler.com.br/textos/ baudelaire2.html>. Acesso em: 27 out. 2012.

CAMPOS, Martha Machado (Coord.). Plano de proteção da paisagem da área central de Vitória. Relatório técnico. Vitória: Prefeitura Municipal de Vitória, Única Construtores, Vitória, 2010. 
CAMPOS JUNIOR, Carlos Teixeira de. O novo arrabalde. Vitória: PMV/ Secretaria Municipal de Cultura e Turismo, 1996. $250 \mathrm{p}$.

CARVAlHO, Ana Maria B. Anchieta. Rio de Janeiro: Salamandra, 1989. 120 p.

CULLEN, Gordon. Paisagem urbana. São Paulo: Martins Fontes, 1983. 202 p.

DEL RIO, Vicente. Introdução ao desenho urbano no processo de planejamento. São Paulo: PINI, 1990. $198 \mathrm{p}$.

FERRARA, Lucrécia D'Alesio. O olhar periférico: informação, linguagem, percepção ambiental. 2 ed. São Paulo: EDUSP, 1999, $277 \mathrm{p}$.

Geisel inicia novo capítulo na história de Anchieta. Jornal A Gazeta, Vitória, set. 1977, p. 1.

KOSSOY, Boris. Realidades e ficções da trama fotográfica. São Paulo: Ateliê Editorial, 2002, 149 p.

MATTOS, Sonia Missagia. Anchieta nosso patrimônio. Goiânia: UCG, 2006. 103 p. (Coleção memórias e identidades, 1).

MENDONÇA, Eneida Maria Souza. Instrumentos para ocupação urbana em favor dos referenciais da paisagem. In: ENCONTRO NACIONAL DA ASSOCIAÇÃO NACIONAL DE PÓS-GRADUAÇÃO E PESQUISA EM

PLANEJAMENTO URBANO E REGIONAL (ANPUR), 1 1, 2005, Salvador. Disponível em: <http://www.anpur.org.br/ inicio/index.php/2012-09-13-13-08-43/anais>. Acesso em: 23 de nov. 2015.

FREITAS, José Francisco Bernardino; CAMPOS, Martha Machado; PRADO, Michele Monteiro; ALMEIDA, Renata Hermanny de. Cidade Prospectiva: o projeto de Saturnino de Brito para Vitoria. Vitória: EDUFES; São Paulo: Annablume, 2009. 116 p.

; GOLTARA, Giovani. Transformação do uso do solo e conflito no litoral de Anchieta-ES. In: SEMINÁRIO DE HISTÓRIA DA CIDADE E DO URBANISMO, 12, 2012, Porto Alegre.

NEVES, Luiz Guilherme Santos. Visão de Anchieta. Vitória: Cultural-ES, 1997. 135 p. ; PACHECO, Renato; FERREIRA, Renata e MURARI, Jonas. História, Geografia e Organização Social e Política do Município de Anchieta. Vitória: Brasília, 1995. 133 p.

PRADO, Michele Monteiro. A modernidade e seu retrato: imagens e representações das transformações da paisagem urbana de Vitória (ES) - 1890/1950. In: Cadernos PPG-AU/UFBA, vol. 3, n. 1, 2004.

SANTUÁRIO DE ANCHIETA. Disponível em: <http://www.litoralsulcapixaba.com.br/santuario/santuario>. Acesso em: 28 de out. 2012.

SANTAELLA, Lúcia; NÖTH, Winfried. Imagem: cognição, semiótica, mídia. 4 ed. São Paulo: Iluminuras, 2005. $224 \mathrm{p}$.

SONTAG, Susan. Ensaios sobre fotografia. Lisboa: Dom Quixote, 1986. 178 p.

\section{Nota do editor}

Submissão: 17 jun. 2015

Aprovação: 2 out. 2015 